\title{
EFFECT OF SINGLE AND SHORT-TERM AEROBICS ON SELECTED MENTAL STATE PARAMETRES IN ADULT FEMALES
}

\author{
Ol'ga Kyselovičová ${ }^{1}$, Alena Cepková ${ }^{2}$, Alžbeta Staňová ${ }^{1}$, Tomáš Gregor ${ }^{1}$, Dagmar \\ Lörincziová $^{3}$ \\ ${ }^{1}$ Comenius University in Bratislava, Faculty of Physical Education and Sport \\ ${ }^{2}$ Slovak University of Technology in Bratislava, Faculty of Mechanical Engineering \\ ${ }^{3}$ University of Economics in Bratislava, Centre for Physical Education and Sports
}

\begin{abstract}
Summary: The aim of the study was to determine the degree of the influence of aerobic program on mental state of the trainees after a single and short-term application. We tried to find out the positive effects of an aerobics on the selected parameters of mental state of women that performed aerobics recreationally. Twenty-two healthy women (age $35 \pm 5$ years) were involved in the specific aerobic program with mini trampolines (jumping) over the period of 5 weeks. To measure the psychological parameters a modified questionnaire of type X-STAI was distributed before and after the single work out at the beginning of the study and after the 5 weeks period. Chi-quadrat analysis was used to evaluate the data. The greatest and statistically the most significant differences were recorded in the parameters 'enthusiastic', 'boosted by energy' and 'relaxed', in comparison with the emotions at the beginning and at the end of the lesson in initial measuring. Comparison of changes after the 5 weeks period at the beginning and at the end of the lesson shows statistical significance in all parameters, except 'tired'. No statistical changes occurred at either the beginning or the end of the lesson comparing initial and final phases. Based on the results, we can conclude that specialized aerobic training provokes immediate changes in psychological state of the trainees via increase of their positive and decrease of negative emotions right after the lesson and when compared to its beginning. This leads to a better mental stability and a greater resistance to the influences of outer environment on mental state.
\end{abstract}

Key words: mental state, aerobic activity, mini trampolines, jumping

DOI 10.1515/afepuc-2015-0009

(C) Acta Facultatis Educationis Physicae Universitatis Comenianae 


\section{Introduction}

Stressful situations can provoke emotional reactions, from a cheerful mood up to anxiety, anger and depression (Gurský 2005). Thus, sufficient rest has to be an integral part of a healthy lifestyle; even more, active rest makes it possible to get rid of physical fatigue. That it is why relaxation means intentional activity after great psychological stress. Based on the results of clinical practice, it is obvious that not only mental states and problems cause physiological problems, but also vice versa: physical problems cause discomfort of a psychological nature. It is more and more evident that mental health and physical activity are very closely tied together, and each can exert a significant effect on the other. Mental health can be positively affected by physical exercise, and opposite, individuals involved in physical rehabilitation make greater advances when they have stable, positive mental health (Hillman, 2008).

Regular and systematic physical activity has been shown to influence mental state in many ways. It has been known for many years that regular physical activity brings benefits to individuals with depressive and anxiety symptoms, a fact confirmed in recent studies (Dimeo et al. 2001; Dunn et al. 2001; Leppamaki et al. 2002). The effects of long-term exercise include increased one's responsibility for health, improvement of self-control and mental stability, self-confidence and self-esteem, decreased frustration, tension and stress, resulting in mental refreshment, improving mood, decrease of fatigue, etc. (Herring et al. 2011; Smith et al. 2013; Weinberg \& Gould 2011). On the other hand, short-term physical training has manifested mostly the axiological, antidepressant, tranquilizing, muscle-relaxant, analgesic, and abreactive effects (Gregor 2009). It is generally believed and suggested that aerobic exercise has the greatest mood-boosted effect when it is performed continuously for a prolonged period of time (Schwartz and Kindermann 1992). Decreases in anger, confusion and depression were found with swimming, biking or yoga participation (DiLorenzo et al. 1991; Berger and Owen 1992). Twenty minutes of exercise with the intensities ranging from light to moderate were equally effective in reducing depression and anxiety (Rendi et al. 2008). However, it has not yet been clearly determined how high intensity workouts affect one's mood or anxiety. Additionally, the best forms of physical activity and the specific effects of different exercises have yet to be determined (Shamus et al. 2008).

Therefore, the aim of the study was to determine the influence and to find out the changes in selected parameters of the mental state of the women involved in recreational aerobics - jumping - after a single as well as repeated, but short-term application. We 
supposed the jumping training will evoke sudden changes in the mental state of the women by increasing positive emotions and minimizing negative emotions right after the lesson, compared to the state at the beginning of the lesson, and that the increasingly positive effect on the women mental state can also be observed after repeated, but short-term training.

\section{Methods and design of the study}

Twenty-two healthy women (age $35 \pm 5$ years) were involved in aerobic program on mini trampolines (jumping) over the period of 5 weeks. In the past, $36 \%$ of the participants had been active and took part in sports such as handball, swimming, skiing, volleyball, track and field, and $64 \%$ of them hadn't participated in any active sport before our study; neither high profile, nor performance sport. The frequency of aerobic activities before the start of our research was four times a week in $5 \%, 11 \%$ of participants used to exercise three times a week, $54 \%$ twice a week, $25 \%$ of them trained once a week, and irregularly $5 \%$. In terms of the technical level, the participants can be characterized as advanced, as all of them had already trained aerobics most often for 60 minutes weekly. Fourteen \% of the subjects reported minor health problems, including anaemia, gynaecological problems, thyroid problems and musculoskeletal system disorder. The rest of them claimed to be "overall healthy". Most of the women - $77 \%$ - were participating in aerobic exercise because of the joy, $73 \%$ to lose weight; some of them also mentioned mental relaxation, exercising for health, as well as socializing.

To monitor the mental state we proceeded as follows: 1 . With the collaboration of the psychologist we have designed a table of the most frequent emotions (mental state categories) emerging after the aerobic activity - enthusiastic, boosted by energy, relaxed, stable, tired, tensed, anxious. 2. Two modified questionnaires type X-STAI were created and distributed before and after the single lesson in the initial phase and the final measurements of our study (after the 5 weeks period). Every tested subject had to assign mark 1 to 5 to each of selected emotions: The emotions were evaluated according to a scale. The scale $1-5$ represented the emotions from the lowest to the highest level. While the Questionnaire 1 was completed at the beginning of the lesson, Questionnaire 2 has focused on finding out the changes of selected parameters of the mental state at the end of the jumping lesson. In total forty-four questionnaires were handed out and they were all completed. The adequate mathematicalstatistics methods, such as the Chi-quadrat analysis, and correlation were used to evaluate the data. The statistically significant level was considered to be at $p \leq 0.5$. 


\section{Results}

The analysis of questionnaires gave us the results which enabled us to confirm or on the contrary to refute the hypotheses.

\section{Enthusiasm}

Enthusiasm is an important motivational factor. Based on the questionnaire answers, it could be observed that before the lesson $45.4 \%$ of asked students felt on the level 5 of enthusiasm. Level number 4 was stated by $36.4 \%$, 'slight enthusiasm' was not observed and $9.1 \%$ students stated level 2. Level 1 reported the same number of our participants. As the women came to the lesson mostly enthusiastic and only a small number of them reported they did not feel enthusiastic at all, it can be assumed that the latter came to the lesson to increase their mental state by aerobics. After the lesson $86.4 \%$, students marked level 5 of enthusiasm in the questionnaire. Other levels could be considered as negligible, but we could mention at least level 4 , which was declared by $9.1 \%$ and level number 1 , which was stated by $4.5 \%$. We can also observe that those who were not quite sure about this declaration and marked the level of enthusiasm as level 4 before the lesson reclassified themselves to level 5 of the most enthusiastic students. As the levels 1, 2 and 3 decreased after the lesson to zero, we can assume that the jumping training had the positive influence by increasing the positive emotions after the lesson in comparison to its beginning.

\section{Boosted by Energy}

$36.4 \%$ of women fully identified the level 5 before the single lesson, $18.2 \%$ women marked the level 4, $31.8 \%$ women asked felt 'slightly boosted by energy'. Level 2 was observed in $9.1 \%$ and $4.5 \%$ women felt no energy. After the completion of exercise, $86.4 \%$ felt boosted by the energy and identified with the level 5. A negligible number was achieved by $4.5 \%$ of women who identified with the level 4 and $9.1 \%$ women identified with the level 1. These results could be attributed to physical fatigue after the exercise. A percentage decrease can be perceived for the level 2, 3 and 4 in comparison to the energy stated before the exercise. The majority of answers represented the level 5. An increase by 5 percent to 9.1 $\%$ as achieved for the lowest level of energy (1) before the lesson. The subjects stated that the exercise was physically demanding, therefore, it is obvious that they did not feel boosted by the energy after the exercise. According to this diagram, efficiency of this exercise is significant and it certainly had a great influence on psychological state of the category 'boosted by the energy'. Women claimed themselves that they were so boosted after the 
completion of single exercise that they would manage to complete other four exercises of this type.

\section{Relaxation}

In this parameter, $4.5 \%$ of women stated level 1 and 2 and $45.5 \%$ of participants claimed level 5. $27.3 \%$ of women stated 'slight relaxation' and $18.2 \%$ felt 'more relaxed' before the lesson. $77.3 \%$ of women marked the highest level of relaxation after the lesson, $18.2 \%$ declared level 4 and $4.5 \%$ felt 'the least relaxed'. Such results illustrate positive impact of the jumping program on participants. The emotion of the highest level of relaxation increased after the training by $32 \%$ in comparison to the beginning of the lesson. There was no change in the category of relaxation in level 4, which represented the declaration 'I feel more relaxed'. There was a significant decrease in level 3, which fell to 0. As such only, single aerobic training, we assume, that women who did not feel relaxed at all before and after the exercise and marked level 1 are subject to certain long-term tension, cannot change state.

\section{Stability}

At the beginning of the lesson $50 \%$ of women stated they felt stable to the highest extent. $18.2 \%$ women claimed stability to the level 3 and equal percentage was achieved in the level 4. $9.1 \%$ women felt 'the least stable' and the remaining number (level 2) represented $4.5 \%$ of women. After the exercise $-77.3 \%$ of our participants felt the most stable, right after $-8.2 \%$ women stated level 4 and $4.5 \%$ women claimed the answer 'the least stable', which was represented by 1 woman only. Level 5 increased by nearly $30 \%$ after the completion of the training, level 4 did not change. Twenty $\%$ of women tested maintained the level of stability, and the lowest level decreased by $5 \%$ after the lesson. Thus, it could be concluded that even the worst mental state gradually improves by aerobic training.

\section{Fatigue}

Interestingly, the same number of women $-22.7 \%$ marked level 5 and level 2 at the beginning of the lesson, $27.3 \%$ stated 'slight fatigue', $18.2 \%$ claimed 'the lowest fatigue' and level 4 occurred in 9,1\%. Fatigue can be caused by different factors of a daily regime and thus its presence varied before and after the lesson. It could not be characterized in one definite way. Despite that, we can observe certain diversity in this category after the lesson because $9.1 \%$ of women stated the highest fatigue. $27.3 \%$ felt 'more tired' and 'slightly tired', $22.7 \%$ women felt 'the least tired' and $13.6 \%$ felt 'slightly more tired'. There is no change in the answer 'slightly tired' - which means that the mean value remained stable.

As it was mentioned before, fatigue can be influenced by several factors that may not be caused by training, such as physical state, work obligations, etc. $18 \%$ of women felt the 
least fatigue before the training and $22 \%$ of them after the training, which is not considered as a significant change. Either we may assume that after the lesson women did not feel fatigue due to $\beta$-carotenes whose level was not measured or they considered the lesson as less demanding. Although some of them were not tired before the lesson, they could change their answers after the lesson. On the contrary, women who felt tired before the lesson might have felt 'boosted by energy' after the lesson. There is no change in the answer 'slightly tired' which means that the mean value remained stable. We assume that women with a better physical condition felt lower fatigue and therefore marked lower levels in the questionnaires.

\section{Tension}

Tension at level 1 was shown by the greatest number of participants at the beginning of the lesson, and this, $68.2 \%$. The greatest tension was felt by the participants in a percent representation of $9.1 \%$, the same number as the moderate scale, and level 4 appeared in 13.6 $\%$ of the questioned exercisers. At the end of the lesson, the tension had almost disappeared; level 1 , and so the least tension, was shown by $81.8 \%$ of the whole group, which represents 18 participants of 22 possible. $9.1 \%$ of the participants appeared 2 times, and this in levels 2 and 5. In the state of tension, we notice a significant difference in the lowest level. Specifically, we see a percent increase of $14 \%$ in level 1 . We evaluate that with the participants who experienced tension in the various levels after the exercised lesson, this state dropped to level 1, and thus its percent was increased. These participants did not experience tension either at all, or to the lowest level possible. A certain part, specifically $9 \%$ of them, ranked in level 2 and the same $9 \%$ experienced the greatest tension both before and after the exercise, which we presume it is possible to decrease by long-term aerobics training.

\section{Anxiety}

A similar case was shown with the issue of anxiety. At the beginning of the lesson $77.3 \%$ of the participants responded that they did not feel anxious. The moderate anxiety was felt by $9.1 \%$, and level 2 was indicated by $4.5 \%$. Level 4 did not appear at all in this question. At the end of the lesson, the question of anxiety had the following result: $90.9 \%$ for level number 1 - no anxiety, and $9.1 \%$ for the highest level, which again could be due to the inattention of the participants. The participants who experienced a certain anxiety before the lesson, said that this state disappeared after the exercise, or experienced only very moderately (level 1) with $91 \%$. Either the remaining $9 \%$ of the participants have felt anxious for a long while or due to inattention, they stated the opposite level than they intended.

In general, we can state that the greatest and statistically the most significant differences were recorded in the parameters 'enthusiastic', 'boosted by energy' and 'relaxed', 
in comparison with the emotions at the beginning and at the end of the jumping lesson in initial measuring as shown in Table 1. Comparison of changes after the 5 weeks period at the beginning and at the end of the lesson shows statistical significance in all parameters, except 'tired' (Table 2). Surprisingly, no statistical changes occurred either at the beginning (Table 3) or the end (Table 4) of the lesson comparing initial and final phases.

Table 1

Statistical significance of mental states changes before the 5 weeks period at the beginning and at the end of the lesson

\begin{tabular}{|l|l|l|l|}
\hline State & Mental State Category & Chi-quadrat & Significance \\
\hline 1 & Enthusiastic & $7.397^{*}$ & $\mathrm{p} \leq 0.05$ \\
\hline 2 & Boosted by energy & $16.34^{* *}$ & $\mathrm{p} \leq 0.01$ \\
\hline 3 & Relaxed & $8.960^{*}$ & $\mathrm{p} \leq 0.05$ \\
\hline 4 & Stable & 3.426 & $\mathrm{~ns}$ \\
\hline 5 & Tired & 4.557 & $\mathrm{~ns}$ \\
\hline 6 & Tensed & 4.606 & $\mathrm{~ns}$ \\
\hline $\mathbf{7}$ & Anxious & 3.243 & $\mathrm{~ns}$ \\
\hline
\end{tabular}

Table 2

Statistical significance of mental states changes after the 5 weeks period at the beginning and at the end of the lesson

\begin{tabular}{|l|l|l|l|}
\hline State & Mental State Category & Chi-quadrat & Significance \\
\hline 1 & Enthusiastic & $16.40^{* *}$ & $\mathrm{p} \leq 0.01$ \\
\hline 2 & Boosted by energy & $14.17^{* *}$ & $\mathrm{p} \leq 0.01$ \\
\hline 3 & Relaxed & $15.87^{* *}$ & $\mathrm{p} \leq 0.01$ \\
\hline 4 & Stable & $11.45^{*}$ & $\mathrm{p} \leq 0.05$ \\
\hline 5 & Tired & 2.900 & $\mathrm{~ns}$ \\
\hline 6 & Tensed & $16.50^{* *}$ & $\mathrm{p} \leq 0.01$ \\
\hline $\mathbf{7}$ & Anxious & $8.324^{*}$ & $\mathrm{p} \leq 0.05$ \\
\hline
\end{tabular}

Table 3

Statistical significance of mental states changes comparing initial and final phases at the beginning of the lesson

\begin{tabular}{|l|l|l|l|}
\hline State & Mental State Category & Chi-quadrat & Significance \\
\hline 1 & Enthusiastic & 6.920 & $\mathrm{~ns}$ \\
\hline 2 & Boosted by energy & 1.054 & $\mathrm{~ns}$ \\
\hline 3 & Relaxed & 3.712 & $\mathrm{~ns}$ \\
\hline 4 & Stable & 3.116 & $\mathrm{~ns}$ \\
\hline 5 & Tired & 5.232 & $\mathrm{~ns}$ \\
\hline 6 & Tensed & 6.085 & $\mathrm{~ns}$ \\
\hline $\mathbf{7}$ & Anxious & 5.238 & $\mathrm{~ns}$ \\
\hline
\end{tabular}


Table 4

Statistical significance of mental states changes comparing initial and final phases at the end of the lesson

\begin{tabular}{|l|l|l|l|}
\hline State & Mental State Category & Chi-quadrat & Significance \\
\hline 1 & Enthusiastic & 2.417 & ns \\
\hline 2 & Boosted by energy & 1.338 & ns \\
\hline 3 & Relaxed & 2.410 & ns \\
\hline 4 & Stable & 1.477 & ns \\
\hline 5 & Tired & 2.469 & ns \\
\hline 6 & Tensed & 3.378 & ns \\
\hline $\mathbf{7}$ & Anxious & 1.072 & ns \\
\hline
\end{tabular}

\section{Discussion}

The goal of our study was to determine the influences of the jumping program on the psychological state of the trainees. We monitored the psychological responses to the selected program after a single lesson and after a 5-week period. Our results show immediate changes in all investigated parameters, but we can consider as statistically meaningful only emotions 'enthusiastic', 'boosted by energy' and 'relaxed'.

Several authors agree with the positive effects of aerobics on tension and relaxation, which is agreement with Krrivohlavý (2001) who considers the physical activity the simplest, most natural and mainly healthiest form of decreasing stress. Improvement in psychological state, enthusiasm and full energy also confirm the findings of Weinberg and Gould (2007) who reveals a rise in the level of endorphins after 30 minutes of sustained persevering activity. Therefore, in general we can state that the result of even single aerobic training brings about positive changes of mood, and we can monitor the anxiolytic and the abreactive effects. Statistically significant differences were not proved in negative emotions, which were limited to the sincere responses of the participants, and it is possible that they were ashamed to admit their negative emotions. The parameter of fatigue, which we investigated, was not conclusive, and therefore cannot be objectively characterized from the subjective evaluations of the participants. As we have already mentioned the fatigue in the daily schedule was influenced by various factors. Therefore, the variability of this parameter was different before and after the lesson. The heterogeneity of the group as regards functional capacity of the organism could also have an effect on the participants' fatigue. Many of the participants could feel physical tiredness after the lesson's exercising while being psychically full of energy. Similarly, the rigorousness of the exercise and progressively increasing burdening could also influence fatigue. Additionally, Weinberg and Gould (2007) state that with every regular 
movement activity with duration of minimum 3 months certain psychic changes are displayed. These effects of the movement activity are described as improvements in psychological stability, mood, increased self-confidence, reduced tension and negative emotions. Fialová (2006) agrees that long-term psychological changes also bring about better resistance to fatigue, and its more rapid decline.

In our study, we attempted to find out whether a short-term aerobics program of 5 weeks' duration would also have a significant influence on psychological changes in the organism. In our final phase measuring, we found highly significant differences in all parameters with the exception of fatigue. We recorded positive changes in emotions of both a positive and negative characters at the beginning and the end of the single lesson. Therefore, we demonstrated the anti-depressive and tranquillizing effects of the aerobics activity as Fialová (2006) and Gregor (2013) confirm it. The results of our study expressed the significant differences in the stability parameter after completing the jumping exercises. The findings, however, did not confirm greater resistance to fatigue even after five weeks of regular aerobic straining.

The study demonstrates also an increase in positive emotions after the completion of an hour of jumping at the initial as well as the final phase of the study. Mutual comparison at the beginning and at the end of the lesson however did not yield statistically significant differences among the individual parameters. Thus, we can state that according to our results jumping has a positive influence on the actual change of the selected parameters of the investigated psychological states. Our results however did not prove that a significantly longterm improvement of these parameters was achieved due to its effect.

We can compare our results with Mandáková (2000) who states that aerobics of any type is a suitable instrument for gaining a positive psychological state and recommends it as an accessible means of psycho-regulation. The results of her study showed the positive influence of various aerobic programs and the improvement of the psychological state after the lesson. After 24 hours, however the state again worsened. Similarly, Chovanec (2013) demonstrated the positive effect of movement activity on managing stress. He postulated that aerobic training secures more effective stress management. Hižnayová (2009) found the positive effect of dance on the psyche in the sense of experiencing positive emotions. The results of her research demonstrated that $93 \%$ of the participants felt a positive change of mood under the influence of dance training, and therefore a more frequent experiencing of positive emotions through dancing. 


\section{Limitation of the study}

To demonstrate the results we used the response method by means of the participants' subjective answers in a specially prepared questionnaire. Therefore, our results could be distorted by the subjective answers of those participants who were not necessarily always sincere, in particular in the questions regarding negative emotions. Similarly, in a few cases it could have been due to the inattention of the participants as regards the consistent reversing of the evaluations scale higher resistance to fatigue, as well as its more rapid decline, should have been secured through long-term psychic changes. However, our results had a variable range and did not show a marked reduction in fatigue, neither at the beginning nor at the end of the research. Since they consisted of subjective responses, it was not possible to monitor them precisely. We also make a distinction between physical and psychic fatigue; while the participants may have felt physically tired, psychically they were 'full of energy'. The fatigue factor may also be influenced by the rigorousness of the exercise lesson prior to the output measuring, which was designed to be more demanding, and so could have an influence on the results in the selected parameter of fatigue. We also presumed a significant difference in the change of psychological state before measuring at the beginning of the input and output lessons. We found no statistical significance in their comparison however. The psychological state in which the trainees came to the gym can be reflection of their daily schedule and can differ in each measuring. The psychological state in which the trainees came to the gym can be reflection of their daily schedule and can differ in each measuring. The results of the input measuring may also be distorted since it was not their very first lesson.

\section{Conclusions}

In our study, we focused on the influence of the specific aerobic program on the psychological state of adult women engaged in recreational sport. Thus, regarding to our results we can formulate the following conclusions:

- The influence of specific aerobic training - jumping - manifested significant positive effects on the psychological state through an increasing of positive emotions and minimizing of negative emotions immediately after the end of a lesson in comparison with its beginning.

- In contrary, an increased positive influence on selected psychological state parameters by repeated, even short-term regular aerobic training was not manifested by statistically significant differences in comparison with initial and final measurements. 
Thus, the stated hypothesis in which we presumed that the repeated short-term activity would have an increased positive effect on the psychological state was not confirmed.

\section{References}

1. BERGER, B.G. and D.R. OWEN, 1992. Mood alteration with yoga and swimming: aerobic exercise may not be necessary. Percept Mot Skills, 75, p. 1331-1343.

2. DiLORENZO, T.M., E.P. BARGMANN, R. STUCKY-ROPP, G.S. BRASSINGTON, P.A. FRENSCH and T. LaFONTAINE, 1991. Long-term effects of aerobic exercise on psychological outcomes. Preventative Medicine, 28, p. 75-85.

3. DIMEO, F., M. BAUER, I. VARAHRAM, G. PROEST and U. HALTER, 2001. Benefits from aerobic exercise in patients with major depression: a pilot study. $\mathrm{Br} J$ Sports Med 35(2): 114-7.

4. DUNN, A.L., M.H. TRIVEDI and H.A. O’NEAL, 2001. Physical activity doseresponse effects on outcomes of depression and anxiety. Med Sci Sports Exerc; 33(6 Suppl): 587-97.

5. FIALOVÁ, L., 2006. Moderní body image. Praha: Grada.

6. GREGOR, T., 2009. Šport a jeho vplyv na osobnost’ človeka. Revue medicíny v praxi, 8(1).

7. GREGOR, T., 2013. Psychológia športu. Bratislava: Mauro.

8. GURSKÝ, T., 2005. Psychológia športu pre trénerov - učebné texty. Bratislava: Telovýchovná škola SZTK.

9. HILLMAN, Ch., 2008. Be smart, exercise your heart: exercise effect on brain and cognition. Nat. Rev. Neurosci 9(1), p. 58-65.

10. HIŽNAYOVÁ, K., 2009. Tanec a jeho pôsobenie na psychiku a emócie tanečníka [online] Publikované. [cit. 2014-03-20] Dostupné z: < http://www.elearning.ktvs.pf.ukf.sk/publikacie/CD_Sport_zdravie_2009/prispevky/Hi znayova.pdf $>$

11. CHOVANEC, L., 2013. Vplyv pohybovej aktivity na zvládnutie stresu: diplomová práca. Bratislava: Univerzita Komenského.

12. Kட̌IVOHLAVÝ, J., 2001. Psychológie zdraví. Praha: Portál. ISBN 80-7178-551-2.

13. LEPPAMAKI, S.J., T.T. PARTONEN, J. HURME, .J. K. HAUKKA and J.K. LONNQVIST, 2002. Randomized trial of the efficacy of bright-light exposure and aerobic exercise on depressive symptoms and serum lipids. J Clin Psychiatry 63(4): 
316-21.

14. MANDÁKOVÁ, M., 2000. Vplyv rôznych druhov aerobiku na psychický stav cvičeniek: diplomová práca. Bratislava: Univerzita Komenského.

15. RENDI, M., A. SZABÓ, T. SZABÓ, A. VELENCZEI and A. KOVÁCS, 2008. Acute psychological benefits of aerobic exercise: a field study into the effect of exercise characteristics. Psych Health Med., 13(2), p. 180-184.

16. SHAMUS, E., S.A. RUSSO, C. FIELDS, G. PEAL, S.Q. MARIKLE and R.D. BUTLER, 2008. Exercise and mental health: psychological benefits. Oste. Fam. Phys. News. ACOFP, 8(5):1, p. 6-8.

17. SCHWARTZ, L.and W. KINDERMANN, 1992. Changes in beta-endorphins levels in response to aerobic and anaerobic exercise. Sport Med. 13, p. 25-36.

18. WEINBERG, R.S. and D. GOULD, 2007. Foundation of Sport and Exercise Psychology. Fourth edition. 607. p. 